\title{
Wind as a Mechanical Stimulus Affect the Rate of Early Reproductive Development in Sunflower (Helianthus annuus L.)
}

\author{
Luis F. Hernández \\ Lab. de Morfología Vegetal, Depto. de Agronomía, \\ Universidad Nacional del Sur, 8000 Bahía Blanca \\ CIC, Pcia. de Buenos Aires, 1900 La Plata. Argentina
}

\begin{abstract}
The present work deals with the effect of wind on sunflower (Helianthus annuus L.) plants at early stages of the reproductive development on the rate of floral differentiation.

Plants were grown under artificial lighting in $2 L$ pots containing soil appropriately fertilized, with a light/dark regime of $18+6 \mathrm{~h}$. Fifteen days after emergence (DAE) three treatments were performed. Wind, where free plants were exposed for $4 \mathrm{~h} /$ day during the light interval, Ih after irrigation, to a continuous air current of 5 $m . s^{-1}$ (WS-1) or $8 \mathrm{~m} \cdot \mathrm{s}^{-1}$ (WS-2) at the apical level and control (C, staked plants) were plant were kept still during the whole experimental period. Starting at 20 DAE reproductive development was studied. At harvest (48 $D A E$ ) leaf area, aerial (stem+leaves) dry weight, stem length and the flexural stiffness of first internode (FSFI) were determined.

Plants from treatment WS-1 showed reductions in leaf area (2.5\%), stem height (10.3\%) and aerial dry weight (16.1\%) compared to control plants. Plants from treatment WS-2 showed reductions in leaf area (26.9\%), stem height $(20.6 \%)$ and increase in aerial dry weight $(11.6 \%)$ compared to control plants. The FSFI was similar in WS-1 and WS-2, with values of 0.022 and $0.025 \mathrm{~N} . \mathrm{m}^{2}$, respectively but significantly higher $(p<0.05)$ than in control plants $\left(0.015 \mathrm{~N} . \mathrm{m}^{2}\right)$. In wind-treated plants the rate of reproductive development (floral stage or FS) was significantly delayed $(P<0.05)$, decreasing from 0.26 units of FS.day ${ }^{-1}$ in C to 0.23 units of FS.day ${ }^{-1}$ in WS-1 and 0.16 units of FS.day ${ }^{-1}$ in WS-2, extending in the latter cases the attainment of FS 5 in 2.9 days and 7.8 days, respectively compared to control plants. A numerical model of the young sunflower stem under dynamic lateral action was studied. Based on its external dimensions and distribution and mechanical properties of its constitutive tissues, a 3-D finite element model of the stem was built. Bending due to lateral wind load was simulated. Stresses and strains generated in the surface and inside the stem were calculated.

Morphological changes observed during the present study can be attributed to thigmomorphogenetic responses and internal hormonal regulation caused by stem bending and leaf movement by wind action. Stem bending in the simulation generates a significant mechanical stress at vascular level. These observations could help to explain why a mechanical perturbation is highly effective to induce physiological and growth changes at early stages of plant development.
\end{abstract}

Keywords: Finite element method; flowering retardation; Helianthus annuus; stem flexural bending; sunflower; thigmomorphogenesis; wind.

\section{INTRODUCTION}

Mechanical perturbations (MP) of different magnitudes applied on plants generate important changes in their development and morphology (Grace, 1977; Telewski, 1995; Jaffe et al., 2002; Kin \& Ledent, 2003), including a delay in internodal elongation (Biddington, 1986; Depege et al., 1997; Sanyal \& Bangerth, 1998; Telewski, 1990;Telewski \& Pruyn, 1998), which results in shorter and stronger stems or a reduction in the leaf area. Moreover, an increase in root diameter and a delay in the reproductive development can be observed (Biddington, 1986; Giridhar \& Jaffe, 1988; Niklas, 1998; Braam \& Davis, 1990; Latimer, 1991; Latimer \& Beverly, 1993; Mitchell \& Myers, 1995; Johnson et al., 1998; Kin \& Ledent, 2003).

Jaffe $(1973,1980)$ used the term thigmomorphogenesis (TMG) to describe the physiological and morphological responses associated with a MP produced by rubbing, pressing and flexing of leaves and stems.

Wind, the most common natural force that acts with different intensities on any crop, may importantly impact on growth and survival of plants (Grace, 1977; Kin \& Ledent, 2003) by inducing an increase in the supporting tissues, a significant reduction in the height/diameter of stem and thus increasing 
their mechanical resistance, for example to lodging (Telewski \& Jaffe 1986a, 1986b; Jaffe \& Forbes, 1993; Telewski 1995; Mitchell, 1996).

To investigate the effect of the wind-induced MP, plants have been manipulated by rubbing, vibrating, shaking or flexing of stems (Jaffe, 1973; Telewski \& Jaffe, 1986a; Niklas, 1998; Cipollini, 1999; Pruyn et al., 2000).

In Arabidopsis thaliana plants, as in other plant species (Biddington, 1986; Giridhar \& Jaffe, 1988) a delay in flowering as well as inhibition of stem and inflorescence lengths have been reported as a result of mechanical stimulation (Braam \& Davis, 1990; Johnson et al., 1998)

Evidence regarding the response of vegetative development of young sunflower plants by the effect of stem flexion indicates that important morphological modifications, such as changes in the leaf surface and significant increase in the stem diameter occur (Whitehead, 1962; Patterson, 1992; Peacock \& Berg, 1994; Goodman \& Ennos, 1996; Smith \& Ennos, 2003). However, being sunflower a sensitive species to respond to mechanical stimuli, almost nothing is known about how a wind-induced MP affects the reproductive development.

Changes in the differentiation rate of floret primordia in sunflower have been reported as a result of the exogenous application of the plant growth regulators benzyladenine (BA), gibberellin $\left(\mathrm{GA}_{3}\right)$ and the auxin indole acetic acid (IAA; Hernández, 1996). Given that TMG modifies the endogenous levels of some of these growth regulators (Beyl \& Mitchell, 1977; Erner \& Jaffe, 1982; Biro \& Jaffe, 1984; Sanyal \& Bangerth, 1998; Aloni et al., 2005), changes in the rate of reproductive development could be expected.

The aim of the present study was to quantify morphologically the wind effect at early stages of reproductive development in sunflower plants on the rate of floral differentiation of the capitulum.

Also, in the present contribution it is hypothesized that stem bending in sunflower induces to a significant internal mechanical stress at vascular level that could help for the rapid long distance intra plant signaling transport that generates any observed morphophysiological change. For validating this, tensions and compressions generated in the young sunflower stem were located and calculated using a dynamic model of stem bending and the finite element (FE) method.

\section{MATERIALS AND MeTHODS}

\subsection{Plant material and wind treatment}

Sunflower (Helianthus annuus L.) plants (hybrid cultivar Dekasol 4030, Monsanto Seeds, Argentina) were grown in the greenhouse in $2 \mathrm{~L}$ plastic pots containing appropriately fertilized soil. Pots were located under a panel of 12 Sylvania $110 \mathrm{~W}$ Cool White fluorescent tubes with a photoperiod of $18+6$ (light/darkness). The amount of PAR provided by the light panel was $285 \pm 18 \square \mathrm{mol} \cdot \mathrm{m}^{-2} \cdot \mathrm{s}^{-1}$. Average air temperature during the experiment was $26.7 \pm 1.7^{\circ} \mathrm{C}$. Throughout the experiment, the pots were kept at field capacity by drip irrigation to overcome the wind effect over an increased evapotranspiration.

Five days after emergence (DAE) the plants were separated in three groups corresponding to treatments $\mathrm{C}$ (control, $\mathrm{n}=30$ ) and $\mathrm{W}$ (wind, $\mathrm{n}=60$ ). Each control plant was gently staked fixing them with two silicone rubber bands to a $30 \mathrm{~cm}$ aluminum rod $(4 \mathrm{~mm}$ diameter). Plants for the wind treatment were non staked.

From 15 to $38 \mathrm{DAE}$ and $1 \mathrm{~h}$ after watering the pots, non staked plants were subjected to an air flow of $5 \mathrm{~m} \cdot \mathrm{s}^{-1}$ (wind speed (WS-)1; n=30 plants) or $8 \mathrm{~m} \cdot \mathrm{s}^{-1}$ (WS-2; $\mathrm{n}=30$ plants) during 4 hours. The air current was produced by a set of three 12-inch turbo fans and the air flow speed at the apical level was measured with a hand anemometer. In all cases the plots were carefully redistributed under the light panel every 3 days.

From 20 DAE in 5 plants per treatment at a 5-days interval the rate of flower development was evaluated dissecting the apical bud under a stereoscopic microscope.A mean value for the stage of capitulum development (floral stage) for each 5-plant sample was obtained by grading each plant against the ten stage classification scale of Marc \& Palmer (1981). All plants were harvested at 48 DAE. Stem length was measured with a digital caliper. Leaf area was determined on scanned images of each leaf for every sampled plant which were afterwards measured using the software ImageJ (Rasband, 2016). Aerial dry weight (leaves + stem) was obtained in oven-dried samples at $60^{\circ} \mathrm{C}$ for $72 \mathrm{~h}$. This experiment was repeated once. 


\subsection{Biomechanical determinations}

The Young's elastic modulus of the first internode ( $E_{\text {Internode }}$; Niklas, 1992) at the time of the last harvest was calculated using a three-point bending test (Liu et al., 2007) performed in a mechanical testing device for small plant samples (Hernández, 2006). Sections of $4 \mathrm{~cm}$ of the first internode were placed horizontally over two supports that were 2 to $3 \mathrm{~cm}$ apart. Vertical applied forces $(F, \mathrm{~N})$ and resulting deflections $(\delta, \mathrm{m})$ were recorded (Hernández, 2006). Internode sections were tested immediately upon removal from the plants previously coated in silicone oil to prevent tissue dehydration during the test.

Young's modulus was calculated as follows (Gere \& Timoshenko, 1997):

$$
E_{\text {Internode }}=\left(F L^{3}\right) / 48 \delta I_{\text {Internode }}
$$

where $L$ is the length between the supports $(\mathrm{m})$ and $I_{\text {Internode }}$ the axial second moment of area $\left(\mathrm{m}^{4}\right)$ (Gere \& Timoshenko,1997). I Internode was calculated from the internode cross-sectional dimensions assuming it was a sector of a circular ring (see Fig. 1c):

$$
I_{\text {Internode }}=(\pi / 8)\left(\mathrm{R}^{4}-\mathrm{r}^{4}\right)(\text { See Fig. } 3.3 \text { in Niklas, 1992) }
$$

For R, the radius of the internode (see Fig. 2 a-d) were estimated using a digital caliper as an average of three perpendicular measurements. The flexural stiffness of the internode (FSFI) was calculated as the product of $E_{\text {Internode }}$ and $I_{\text {Internode }}\left(\right.$ N.m ${ }^{2}$; Niklas, 1992; Vogel, 1992).

\subsection{Stem Model for Dynamic Analysis}

\subsubsection{Stem Anatomy}

A detailed location of the main tissues within the hypocotyl and epicotyl (Fig. 1a; Esau, 1977) and the surface areas of each constitutive tissue were defined from properly stained transverse serial sections taken from 25-days old $10 \mathrm{~cm}$ length stems (FS2; Marc \& Palmer, 1981) sampled from control plants. Stained cuts were phographed using a Nikon Labophot-2 microscope. In the images measurements were performed using the software ImageJ (Rasband, 2016). The relative volumes of its constitutive tissues were then calculated. For each biomechanical test 10 samples were used.

A

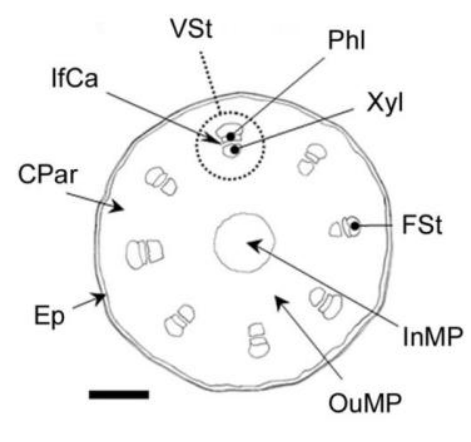

B
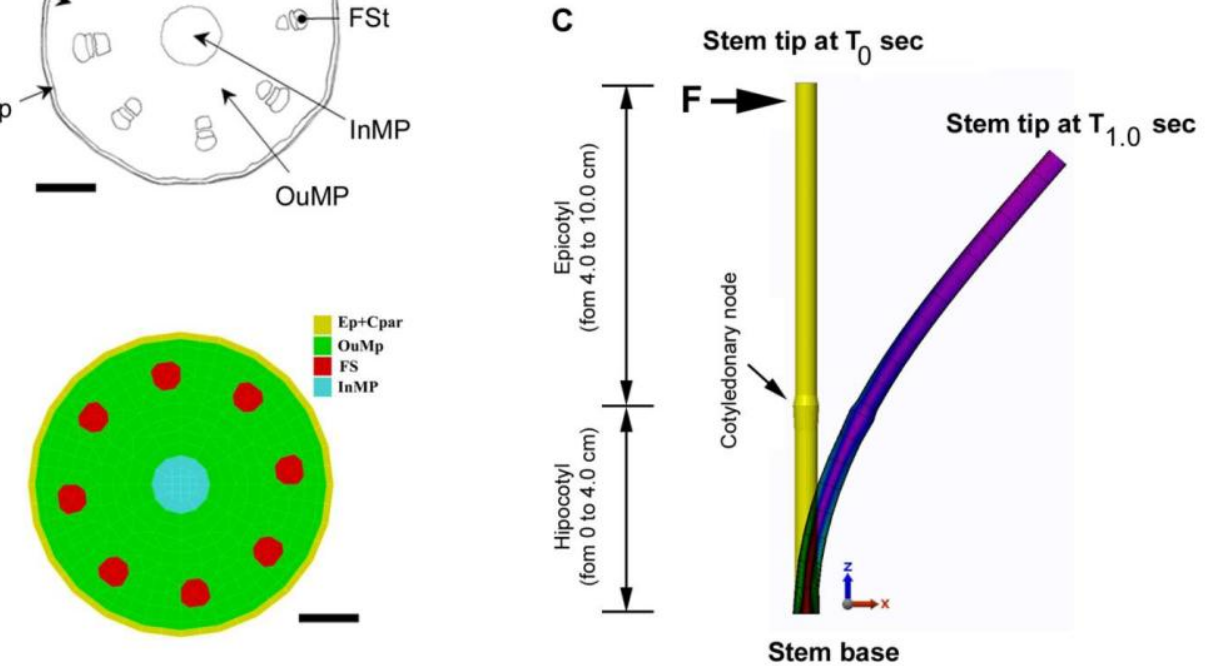

Fig1. a) Histological components (schematic representation) of the young sunflower stem. Ep: epidermis; CPar: cortex parenchyma; IfCa: interfascicular cambium; Phl: phloem; Xyl: xylem; FSt: fiber strand; InMP: inner medullary parenchyma; OuMP: outer medullary parenchyma; VSt: vascular strand. b) Meshed model of a. The 3-D model was constructed as an uniaxial z projection of the 2-D meshed model, with vascular tissue composed by 8 strands along the epi and hypocotyl. The scale identifies the 4 material groups in the model. c) Shape and dimensions of the FE model at the beginning $\left(T_{0 \mathrm{sec}}\right)$ and at the end $\left(T_{1.0 \mathrm{sec}}\right)$ of the simulation. Arrow in " $F$ " indicates the direction of the applied force $(2 N)$ during the bending simulation. Scale bar in a and $b=$ $1.0 \mathrm{~mm}$. 


\subsubsection{Biomechanical Properties of the Tissues}

The Young's modulus [E, (MN)] of epidermis and parenchyma as well as its Poisson ratios $(\sigma)$ and density $\left[\delta,\left(\mathrm{Kg}_{\mathrm{g}} \mathrm{m}^{-3}\right)\right]$ were taken from the literature (Preston, 1974; Smith \& Ennos, 2003; Wainwright et al., 1982). The Young's modulus of the fiber strands was taken from Hepworth \& Vincent (1998). Tissue density was estimated from the weight of stem segments of known dimensions and the relative proportions of each tissue calculated as described above.

\subsubsection{Modeling and Stress Simulation}

Stresses inside the stem were calculated using the finite element (FE) method (Logan, 2001). This is a numerical procedure used for both static and dynamic structural analyses, suited for solving the partial differential equations which describe stresses and strains in structures which have heterogeneous properties.

Based on the distribution of tissues (Fig. 1a) and its real external dimensions and geometry (Fig. 1c) a $3-\mathrm{D}$ model of the stem was constructed and properly meshed using the brick structural element (Logan, 2001; Hernández, et al., 2007) (Fig. 1b-c). The anatomy of the sunflower stem at early developmental stages is fairly regular from tip to base so eight strands of vascular tissue in the hypocotyl $(0$ to $4.0 \mathrm{~cm})$ and epicotyl $(4.0$ to $10.0 \mathrm{~cm}$; Fig. 1c) as observed from the histological analysis were considered in all its length. Even though it is known that the strengthening tissues in stems are highly anisotropic (Niklas, 1992), for simplification purposes the model assumes isotropy and was considered to be composed by four tissues (Fig. 1b) incorporated as four independent element groups of isotropic material: epidermis $(\mathrm{Ep})+$ cortex parenchyma (Cpar): $E=3.6 ; \sigma=2.5 ; \delta=$ 390; outer medullary parenchyma (OuMP): $E=6.8 ; \sigma=0.25 ; \delta=1010$; fiber strand (FSt): $E=10.1 ; \sigma=2.8$; $\delta=1000$; inner medullary parenchyma (InMP): $E=3.4 ; \sigma=3.5 ; \delta=570$; Fig. 1a). Six and eight-nodal solid elements were used giving the model a final configuration of 12356 elements with 9347 nodes (Fig. 1c).

\subsubsection{Calculation and Localization of Stresses in the Model}

Stresses at the site of the hypocotyl's simulated uniaxial bending were calculated. The analysis was made using the ACCUPACK/VE routine from ALGOR (vers. 17, Algor Inc., Pittsburgh, PA; Hernández \& Bellés, 2007; Hernández et al., 2007), a FE software processor for non-linear calculation to conduct a mechanical event simulation (MES).

The bottom of the hypocotyl model was fixed and bending stresses during MES applying a displacement boundary condition ( $\mathrm{F}=0.0$ to $2.0 \mathrm{~N}$ during $1.0 \mathrm{~s}$; Fig. 1c) at the opposite apical end were registered at a capture rate of $130 \mathrm{steps} \cdot \mathrm{sec}^{-1}$. The force applied was assumed to be enough to induce bending in field grown sunflower plants of the same age exposed to mild wind (Smith \& Ennos, 2003; L. Hernández, unpublished results) and to keep the analysis in the domain of elasticity of the tissues included in the simulation.

\subsubsection{Statistical Procedures}

Wind experiments were devised as a completely randomised design with two replicates. Statistical differences between treatments for all parameters evaluated were estimated applying the one-way analysis of variance (ANOVA) test at the $1 \%$ and $5 \%$ level $(\mathrm{P} \leq 0.01$ and $\mathrm{P} \leq 0.05)$ of significance. The Fisher LSD test was used to compare the effect of treatments on floral development attainment at the last three sampling dates. All statistical analyses were performed using the InfoStat program (InfoStat version 2008, National University of Córdoba, Córdoba, Argentina).

\section{RESUlTS AND DISCUSSION}

Plants from treatment WS-1 showed reductions in leaf area $(2.5 \%)$, stem height $(10.3 \%)$ and stem dry weight $(16.1 \%)$ compared to control plants (Table 1). Plants from treatment WS-2 showed reductions in leaf area $(26.9 \%)$, stem height $(20.6 \%)$ and an increase in stem dry weight $(11.6 \%)$ compared to control plants (Table 1). The FSFI was similar in WS-1 and WS-2 treatments, with values of 0.022 and $0.025 \mathrm{~N} . \mathrm{m}^{2}$, respectively but it was significantly higher $(\mathrm{p}<0.05)$ than in control plants $\left(0.015 \mathrm{~N} . \mathrm{m}^{2}\right)$ (Table 1$)$. The rate of reproductive development was significantly delayed, $(\mathrm{P}<0.05)$, decreasing from 0.26 units of EF.day ${ }^{-1}$ in $\mathrm{C}$ to 0.23 units of EF.day ${ }^{-1}$ in WS- 1 and 0.16 units of EF.day ${ }^{-1}$ in WS-2 (Figure 2), extending, in the latter cases, the attainment of EF5 to 2.9 days and 7.8 days, respectively compared to control plants (Table 1 ). 
Wind as a Mechanical Stimulus Affect the Rate of Early Reproductive Development in Sunflower (Helianthus annuus L.)

Table1. Morphological, reproductive and mechanical parameters measured in the control (staked) and windtreated plants.

Treatment

\begin{tabular}{|c|c|c|c|c|c|}
\hline Parameter & Control & $\begin{array}{l}\text { WS-1 } \\
\left(2 \mathrm{~m} \cdot \mathrm{s}^{-1}\right)\end{array}$ & $P$ & $\begin{array}{l}\text { WS-2 } \\
\left(8 \mathrm{~m} \cdot \mathrm{s}^{-1}\right)\end{array}$ & $P$ \\
\hline Stem height $(\mathrm{cm})^{a}$ & $16.5(2.3)$ & $14.8(1.8)$ & $*$ & $13.1(2.1)$ & $* *$ \\
\hline Leaf area $\left(\mathrm{cm}^{2}\right)^{a}$ & $390.3(7.1)$ & $398.7(6.3)$ & NS & $285.5(6.9)$ & $*$ \\
\hline Aerial dry weight $(\mathrm{g})^{\text {a }}$ & $9.31(1.1)$ & $8.74(2.4)$ & NS & $8.23(1.9)$ & NS \\
\hline Time to attain FS5 (days) ${ }^{b}$ & 32.3 & 35.2 & $*$ & 40.1 & $* *$ \\
\hline Young's modulus $(E) \times 10^{8}\left(\mathrm{~N} \cdot \mathrm{m}^{-2}\right)$ & 6.23 & 8.17 & $*$ & 8.72 & $*$ \\
\hline FSFI $(E I)\left(\mathrm{N} . \mathrm{m}^{2}\right)$ & 0.015 & 0.022 & $*$ & 0.025 & $*$ \\
\hline
\end{tabular}

WS-1 (2 m.s $\left.\mathrm{s}^{-1}\right)$ and WS-2 (8 m.s $\left.\mathrm{s}^{-1}\right)$ : wind speed treatments; FSFI: Flexural stiffness of the first internode. FS 5: Floral stage 5, after Marc and Palmer, (1981). Values in brackets are standard errors of the means.

a. Values are pooled means of $n=30$ plants per treatment.

$b$. Values are pooled means of $n=5$ plants pert treatment, measured at FS 8. Level of significance between treatments from analysis of variance are given:

**, significantly different from the control, $P<0.01$ and $*, P<0.05 ; \mathrm{NS}$, not significant $(P>0.05)$.

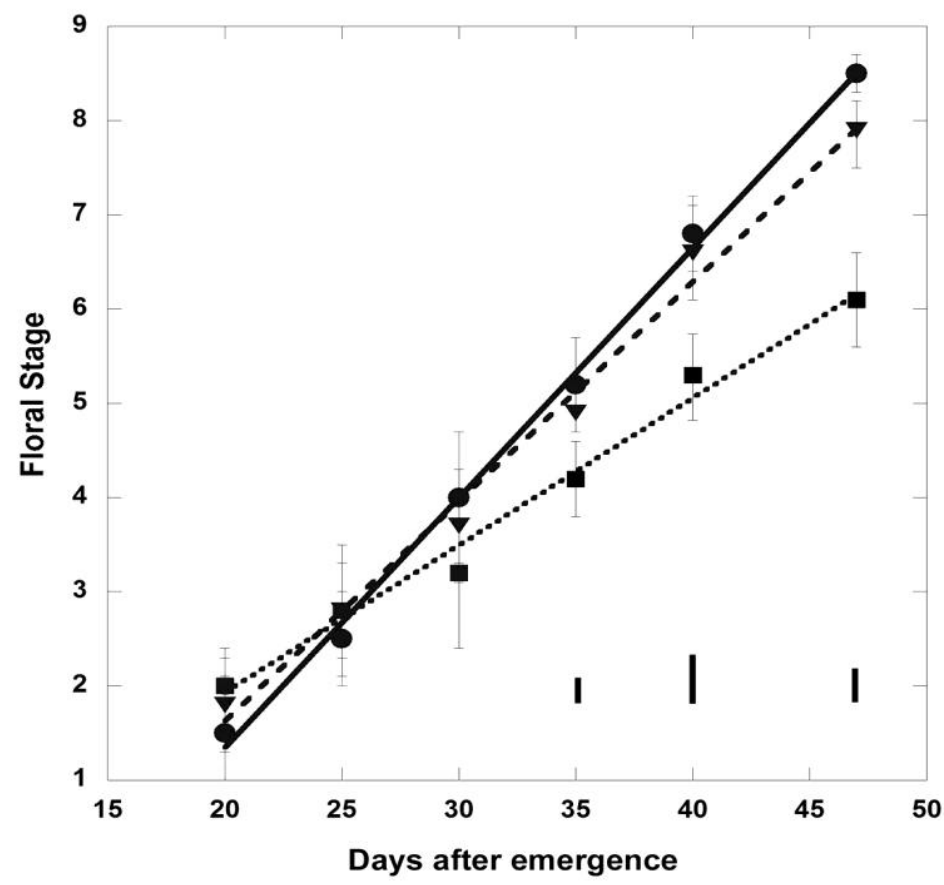

Fig2. Effect of wind speed in controlled grown sunflower plants, hybrid Dekasol 4030 reared in an 18-hr photoperiod, on the rate of post initiation development of the capitulum up to the end of the floret production period (FS8, in control plants). Values are pooled means $\pm S E$ from the two experiments. $N=5$ plants per sampling date and treatment. Vertical bars for the last three sampling dates indicate $L S D(P<0.01)$. A single ordinary least-squares regression line was fit for each treatment. The resultant equations are:

Control: Floral stage $(F S)=3.96+0.27$. Days after emergence $(D A E) ; r^{2}=0.997$

$\left(W S-1 ; 2 \mathrm{~m} \cdot \mathrm{s}^{-1}\right): F S=-3.03+0.23 . D A E ; r^{2}=0.990$

$\left(W S-2 ; 5 m . s^{-1}\right): F S=-1.21+0.16 . D A E ; r^{2}=0.986$ 
In Figure 3 the the distribution of stresses over the stem's surface and inside the stem at a transversal section located in the critical area immediately above the cotyledonary node (over the tapered region of the stem), obtained after the simulated bending of the model are shown. Stress fields outside and inside the stem distributed at the end of the simulated bending are shown in Fig. 3a. The distribution of stresses in a transverse section of the model, superposed with a transverse cut of the stem are shown in Fig. $3 b$.

A

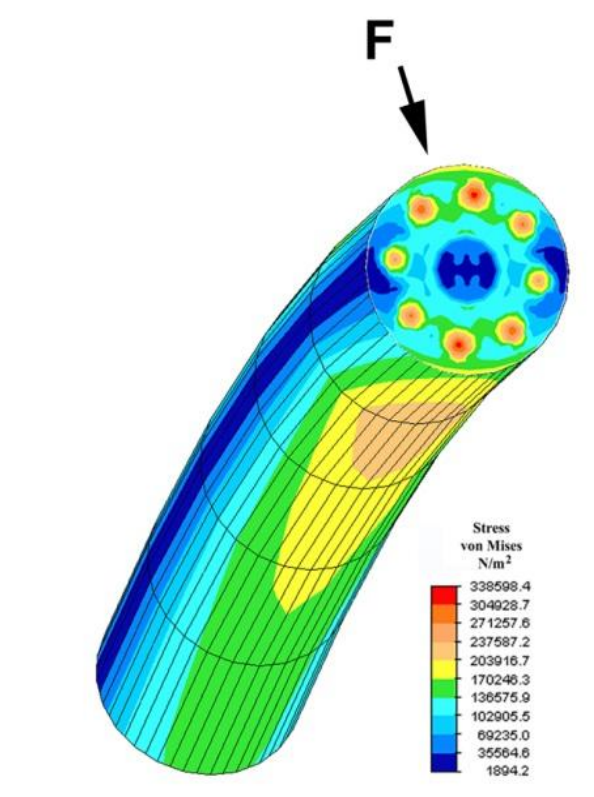

Stem base at $\mathrm{T}_{1.0} \mathrm{sec}$

B

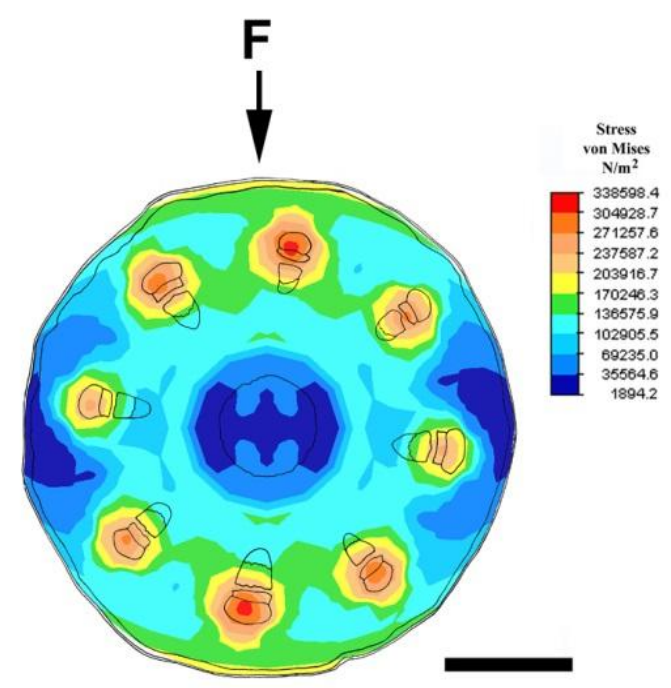

Fig3. $(a-b)$ Calculated stresses (von Mises; $\left.N . m^{-2}\right)$ at the end of the bending simulation $\left(T_{1.0}\right.$ sec $)$ in the modeled stem. Applied force was oriented as in $F$. Note that higher external and internal stress magnitudes are displaced towards the stem base and mainly located near the vascular tissue. c) Stress distribution in the modeled stem superimposed with its correspondent schematic histological arrangement of Fig. la. Note that the higher stress values correspond to the sites where the phloem an mainly the xylem are located. Vertical color bar indicates gradient areas (from maximum, red, to minimum, blue) of von Mises stresses (VMS) in the simulation. This stress unit is frequently used to characterize the stress state (the normal and shear stresses) at a particular point, giving an appreciation of the overall magnitude of the stress tensor (Logan, 2001). It is only physically meaningful for isotropic materials and should not be used in the case of the anisotropic materials involved in the stem structure. Nevertheless, for the purpose of the present study the use of VMS is considered acceptable.Arrow in " $F$ " indicates the direction of the applied force $(2 N)$ during the bending simulation. Scale bar $=1.0 \mathrm{~mm}$ 
It can be seen that the position and the pattern of maximum stress (von Mises; Logan, 2001) values are always significantly higher near the vascular tissue (Fig. 3). This is a consequence of the proximity of the fiber strands which have the highest Young's modulus (FSt: $E=10.1 \mathrm{MN}$ ) to xylem and phloem. Moreover, the sequential results of the dynamic simulation after the completion of maximum bending showed that the highest stress values were near the shoot apical meristem. Then stresses are propagated acropetally.

The significant reduction in the rate of early reproductive development is the most relevant finding of this work and could be explained by many known experimental evidences reported so far (Fig. 2).

Mechanical perturbations are mediated by signaling molecules (Chehab et al., 2009) such as hormones (ethylene, ABA, auxins), secondary messengers nitric oxide and reactive oxygen species (ROS) (Chehab et al., 2009).

In fact the tigmomorfogenesis responses resulting from bending of the stem and leaves motion by wind can be simmilar to those observed after the exogenous application of plant growth regulators (Erner \& Jaffe, 1982; Biro \& Jaffe, 1984). For example, in rubbed stressed plants, GA like activity was reduced compared with non-stressed controls (Beyl \& Mitchell, 1977).

It is known that young sunflower plants are highly sensitive to GA3 (Hernández, 1996). Gibberellins can accelerate the rate of floral development (Pharis \& King, 1985). Also, the cytokinin benzyladenine (BA) promotes and in some cases accelerates inflorescence differentiation in sunflower (Palmer \& Hernández, 1988).

In that way Hernández (1996), observed that GA3 treatments did not produce significant changes in inflorescence morphology except that there was an increase in the rate of floral development of about 0.10 units of FS.day ${ }^{-1}$, the rate increasing from 0.25 units of FS.day ${ }^{-1}$ in the control to 0.35 units of FS.day ${ }^{-1}$ in the GA3-treated plants. As a result, the final stages of inflorescence formation (FS 10) were attained 9 days earlier than in the controls. The onset of flowering was not significantly affected, but the rate of floret differentiation changed with each treatment (Hernández, 1996).

Although it is not clear how a MP regulates the plant's growth and development, several studies reported that changes in the synthesis and further mobilization of endogenous growth regulators are responsible for the thigmomorphogenetic responses (Mitchell \& Myers, 1995). Plant growth regulators involved in this process include ethylene, jasmonic acid and auxins and partially cytokinins (Sanyal \& Bangerth, 1998; Aloni et al., 2005).

It has been reported that mechanical stress also elicits nitrous oxide (NO) formation in Arabidopsis (Garcés et al., 2001) and in sunflower (Chaki et al., 2011). There is also evidence that in Arabidopsis NO can repress the floral transition (He et al., 2001).

Moreover, MP was observed to dramatically reduce the activities of the giberellins, and significantly increase the levels of the abscisic acid (Mitchell, 1996). In addition, Cipollini $(1997 ; 1999)$ found that wind-induced MP may increase the activity of peroxidases enzymes (POD) and cinnamyl alcoholdehydrogenase $(\mathrm{CAD})$. These enzymes are associated with the synthesis and metabolism of lignin, the most important component of supporting and mechanical resistance tissues in plants.

These endogenous hormonal changes would be also regulated by the activity of the specific genes (TCH or "touch genes") induced by brushing or touching (Braam \& Davis, 1990; Botella \& Arteca, 1994; Takezawa et al., 1995; Depege et al., 1997; Borsics \& Lados, 2001). TCH induction would arise not only from an external mechanical stimulation, but it can also be regulated by internal mechanical tensions generated during plant development (Sistrunk et al., 1994).

There is experimental evidence that higher plants have evolved a mechanism that allows the selective translocation of long-distance signaling molecules by the phloem, for delivery to distant organs of the plant (Ruiz-Medrano et al., 1999). Phloem sap contains a wide variety of proteins (Barnes et al., 2004) and some of these proteins that move in the translocation stream could act in signal transduction cascades involved in the integration of developmental and physiological processes occurring within distantly located organs (Jaffe et al., 2002).

The model described in this paper (Fig. 1), a theoretical representation of a juvenile sunflower stem, its constitutive tissues and their biomechanical properties, is able to predict stress distribution patterns 
inside the stem structure (Fig. 3). The proximity of stressed areas to the phloem and xylem elements support the hypothesis that mechanical stimulus cannot only act at the stem surface but also at the vascular tissue level.

To rapidly transduce the thigmo stimulus from the site of perception to distant apical meristems where active cell reproduction and expansion are taking place (Erner et al., 1980), an efficient transport system, other than cell to cell communication pathways via plasmodesmata, has to be available (Jaffe et al., 2002).The phloem long-distance translocation system of plants could play an important role in whole-plant development as a conduit for the delivery of signaling molecules (Jaeger et al., 1988; Yoo et al., 2002). It could then be appropriate to speculate that the vascular system, particularly at the phloem sieve elements level, could be the best route for the signals to be mobilized.

In fact the velocity of movement of materials in the SE range from 0.30 to $150 \mathrm{~cm} \cdot \mathrm{h}^{-1}$ (Taiz \& Zeiger, 2015). In an organ of $10 \mathrm{~cm}$ length such as a plant's hypocotyl, the mechanosignal generated at its base could reach the apical meristem in around $6 \mathrm{~min}$, which closely agrees with the measured times for the mechano-responses (Peacock \& Berg, 1994). Moreover if the mechanical stresses generated by shoot bending are located near the phloem strands it could contribute even more to the mechanostimulus transport efficiency. This would result in endogenous mechanosignals generated near the vascular strands that would then easily move acropetally and basipetally towards growth centers.

Depending on the cultivation area, orientation of crop furrows relative to the prevailing wind direction and crop density, sunflower seedlings at a juvenile stage are often exposed to the action of the wind in plants up to 30 DAE. Shaking and flexing of stems are observed, reaching several times per day a deflection angle of approximately $40^{\circ}$ (Hernández, 2006).

So after the findings reported here, it can be expected that this plant swaying can generate, not only changes in the vegetative growth but a significant delay in the rate of floral primordia differentiation, particularly between FS 5 and FS 8 (Marc \& Palmer, 1981; Fig. 2).

Also the wind effect on flowering in the sunflower could have crop-scale ecophysiological implications. So this should be taken into account when determining water management, fertilization and even orientation of crop rows. In the latter case it should be important to know the direction of prevailing winds in the cultivation area. Even though floral transition is not altered a delay in the completion on time of floral differentiation could lead to an excessive vegetative growth, creating problems with crop protection, delayed anthesis and modifying cultural routines of crop management. This would be important for example in sunflower crops cultured for seed production.

\section{ACKNOWLEDGements}

This work was supported by grants to L.F.H. from the Secretaría General de Ciencia y Tecnología UNS and the Comisión de Investigaciones Científicas (CIC, La Plata) Argentina. The valuable technical assistance in sample processing by Mrs. G.M. Abrego and the collaboration of Civil Engs. P.M. Bellés and T.T. Gómez in the development of the FE model are greatly appreciated. The author has no conflict of interest to declare.

\section{REFERENCES}

[1] Aloni R., Langhans M., Aloni E., Dreieicher E., Ullrich C.I. (2005) Root-synthesized cytokinin in Arabidopsis is distributed in the shoot by the transpiration stream. Journal of Experimental Botany, 56, 1535-1544.

[2] Barnes A., Bale J., ConstantinidouC., Ashton P., Jones A., Pritchard J. (2004) Determining protein identity from sieve element sap in Ricinus communis L. by quadrupole time of flight (QTOF) mass spectrometry. Journal of Experimental Botany, 55, 1473-1481.

[3] Beyl C.A., MitchellC.A. (1977) Characterization of mechanical stress dwarfing in Chrysanthemum. Journal of the American Society for Horticultural Science, 102, 591-594.

[4] Biddington N.L. (1986) The effects of mechanically-induced stress in plants - a review. Plant Growth Regulation, 4,103-123.

[5] Biro L.R., Jaffe M.J. (1984) Thigmomorphogenesis: ethylene evolution and its role in the changes observed in mechanically perturbed bean plants. Physiologia Plantarum, 62, 289-296. 
[6] Borsics T., Lados M.(2001) cDNA cloning of a mechanical/abiotic stress-inducible calmodulinrelated gene from dodder-infected alfalfa. Plant Cell and Environment, 24, 649-656.

[7] Botella J.R., Arteca R.N. (1994) Differential expression of two calmodulin genes in response to physical and chemical stimuli. Plant Molecular Biology, 24, 757-766.

[8] Braam J., Davis R.W.(1990) Rain-, wind-, and touch-induced expression of calmodulin and calmodulin-related genes in Arabidopsis. Cell, 60, 357-364.

[9] Cipollini D.F. (1997) Wind-induced mechanical stimulation increase pest resistance in common bean. Oecologia, 111, 84-90.

[10] Cipollini D.F. (1999) Costs to flowering of the production of a mechanically hardened phenotype in Brassica napus L. International Journal of Plant Science, 160, 735-741.

[11] Chaki M., Valderrama R., Fernández-Ocaña A.M., Carreras A., Gómez-Rodríguez M.V., Pedrajas J.R., Begara-Morales J.C., Sánchez-Calvo B., Luque F., Leterrier M., Corpas F.J., Barroso J.B. (2011) Mechanical wounding induces a nitrosative stress by down-regulation of GSNO reductase and an increase in S-nitrosothiols in sunflower (Helianthus annuus) seedlings. Journal of Experimental Botany, 62, 1803-1813.

[12] Chehab E.W., Eich E., Braam J. (2009) Thigmomorphogenesis: a complex plant response to mechano-stimulation. Journal of Experimental Botany, 60, 43-56.

[13] Depege N., Thonat C., Coutand C., Julien J.L., Boyer N. (1997) Morphological responses and molecular modifications in tomato plants after mechanical stimulation. Plant and Cell Physiology, 28, 1127-1134.

[14] Erner Y., Biro R.Jaffe M.J.(1980) Thigmomorphogenesis: evidence for a translocatable thigmomorphogenetic factor induced by mechanical perturbation of beans (Phaseolus vulgaris). Physiologia Plantarum, 50, 21-25.

[15] Erner, Y., Jaffe M.J. (1982) Thigmomorphogenesis: The involvement of auxin and abscisic acid in growth retardation due to mechanical perturbation. Plant and Cell Physiology, 23, 935-941.

[16] Esau, K. (1977) Anatomy of Seed Plants. JohnWiley \& Sons, New York. 376 p.

[17] Garcés H.,Durzan D., Pedroso M.C. (2001)Mechanical stress elicits nitric oxide formation and DNA fragmentation in Arabidopsis thaliana. Annals ofBotany, 87, 567-574.

[18] Gere J.M., Timoshenko S.P. (1997)Mechanics of Materials, 4th edition, PWS, Boston. 912 p.

[19] Giridhar G., Jaffe, M.J. (1988) Thigmomorphogenesis XXII. Promotion of foliar senescence by mechanical perturbation of Avena sativa and four other species. Physiologia Plantarum, 74, 473480.

[20] Goodman A.M., Ennos A.R. (1996) A comparative study of the response of the roots and shoots of sunflower and maize to mechanical stimulation. Journal of Experimental Botany, 47, 14991507.

[21] Grace J. (1977) Plant responses to wind. Academic Press, New York, 204 p.

[22] He Y.,TangR-H., Hao Y., Stevens R.D., Cook C.W., Ahn S.M., Jing L., Yang Z., Chen L., Guo F., Fiorani F., Jackson R.B., Crawford N.M., Pei Z-M. (2001) Nitric oxide represses the Arabidopsis floral transition. Science, 305, 1968-1971.

[23] Hepworth D.G., Vincent J.F.V. (1998) Modelling the mechanical properties of xylem tissue from tobacco plants (Nicotiana tabacum "Samsun") by considering the importance of molecular and micromechanisms. Annals of Botany, 81, 761-770.

[24] Hernández L.F., Bellés P.M. (2007) A 3-D finite element analysis of the sunflower (Helianthus annuus L.) fruit. Biomechanical approach for the improvement of its hullability. Journal of Food Engineering, 78, 861-869.

[25] Hernández L.F. (1996) Morphogenesis in sunflower (Helianthus annuus L.) as affected by exogenous application of plant growth regulators. Agriscientia, 13, 3-11.

[26] Hernández L.F. (2006) Computation of external and internal mechanical stresses along a sunflower's (Helianthus annuus L.) stem under simulated flexure. Proceedings of the 5th Plant Biomechanics Conference, Stockholm, p. 185-201.

[27] Hernández L.F., Bellés P.M., Gómez T.T. (2007) Finite element modeling of external and internal stresses generated in the sunflower's (Helianthus annuus L.) stem after flexure. 2007 SEM Annual Conference Proceedings, s65.p02. 
[28] INFOSTAT. (2008) InfoStat version 1.1./Professional. Grupo InfoStat, FCA, Universidad Nacional de Cordoba, Cordoba, Argentina.

[29] Jaeger C.H., Goeschl J.D., Magnuson C.E., Fares Y., Strain B.R. (1988) Short-term responses of phloem transport to mechanical perturbation. Physiologia Plantarum, 72, 588-594.

[30] Jaffe M. J.,Leopold A.C., Staples R.C. (2002) Thigmo responses in plants and fungi. American Journal of Botany, 89, 375-382.

[31] Jaffe M.J. (1973) Thigmomorphogenesis: the response of plant growth and development to mechanical stimulation. Planta, 114, 143-157.

[32] Jaffe M.J. (1980) Morphogenetic responses of plants to mechanical stimuli, or stress. Bioscience, 30, 239-243.

[33] Jaffe M.J., Forbes S. (1993) Thigmomorphogenesis: the effect of mechanical perturbation on plants. Plant Growth Regulation, 12, 313-324.

[34] Johnson K.A., SistrunkM., Polisensky D., Braam J. (1998) Arabidopsis thaliana responses to mechanical stimulation do not require ETR1 or EIN2. Plant Physiology, 116, 643-649.

[35] Kin A.G., Ledent J.F. (2003) Efecto del viento sobre las plantas. In: Viento, Suelo y Plantas. p. 47-72. Golberg, A.D., Kin, A.G. (Eds.), INTA Ediciones, Buenos Aires, Argentina.

[36] Latimer J.G. (1991) Mechanical conditioning for control of growth and quality of vegetable transplants. HortScience, 26, 1456-1461.

[37] Latimer J.G., Beverly R. (1993) Mechanical conditioning of greenhouse-grown transplants. HortTechnology, 3, 412-414.

[38] Liu Y., Schieving F., Stuefer J.F., Anten N.P.R. (2007) The effects of mechanical stress and spectral shading on the growth and allocation of ten genotypes of a stoloniferous plant. Annals of Botany, 99, 121-130.

[39] Logan, D.L. (2001) First Course in the Finite Element Method Using Algor, 2nd edition, Brooks-Cole Publishing, Platteville, WI, 912 p.

[40] Marc J., Palmer J.H. (1981) Photoperiodic sensitivity of inflorescence initiation and development in sunflower. Field Crops Research, 4,155-164.

[41] Mitchell C.A. (1996) Recent advances in plant response to mechanical stress: Theory and application. HortScience, 31, 31-35.

[42] Mitchell C.A., Myers P.N. (1995) Mechanical stress regulation of plant growth and development. Horticultural Reviews, 17, 1-42.

[43] Niklas K.J. (1998) Effects of vibration on mechanical properties and biomass allocation pattern of Capsella bursa-pastoris (Cruciferae). Annals of Botany, 82, 147-156.

[44] Niklas K.J. (1992)Plant Biomechanics. Univ. of Chicago Press, Chicago, 607 p.

[45] Palmer J.H., Hernández L.F.(1988) Techniques to change the number of floret and seed rows in the sunflower capitulum. 12th International Sunflower Conference Proceedings, Novi Sad, Yugoslavia, Vol. 1, p. 156-158.

[46] Patterson M. (1992) Role of mechanical loading on the growth of sunflower (Helianthus annuus) seedlings. Journal of Experimental Botany, 43, 933-939.

[47] Peacock K., Berg A.R. (1994) Effect of mechanical stress on sunflower (Helianthus annuus L.) hypocotyl growth. Annals of Botany, 74, 661-666.

[48] Pharis R.P., King R.W.(1985) Gibbebrellins and reproductive development in seed plants. Annual Review of Plant Physiology, 36, 517-568.

[49] PrestonR.D. (1974) The Physical Biology of Plant Cell Walls. Chapman, London. 491 p.

[50] Pruyn M.L., Ewers III B.J., Telewski F.W.(2000) Thigmomorphogenesis: changes in the morphology and mechanical properties of two Populus hybrids in response to mechanical perturbation. Tree Physiology, 20, 535-540.

[51] Rasband W.S. (2016)ImageJ, U. S. National Institutes of Health, Bethesda, Maryland, USA, http://imagej.nih.gov/ij/

[52] Ruiz-Medrano R., Xoconostle-Cázares B., Lucas W.J.(1999)Phloem long-distance transport of CmNACPmRNA: implications for supracellular regulation in plants. Development, 126, 44054419. 
[53] Sanyal D., Bangerth F. (1998) Stress induced ethylene evolution and its possible relationship to auxin-transport, cytokinin levels, and flower bud induction in shoots of apple seedlings and bearing apple trees. Plant Growth Regulation, 24, 127-134.

[54] Sistrunk M.L., Antosiewicz D.M., Purugganan M.M., Braam J. (1994) Arabidopsis TCH3 encodes a novel $\mathrm{Ca} 2+$ binding protein and shows environmentally induced and tissue-specific regulation. The Plant Cell, 6, 1553-1565.

[55] Smith V.C., Ennos A.R. (2003) The effect of air flow and stem flexure on the mechanical and hydraulic properties of the stems of sunflowers (Helianthus annuus L). Journal of Experimental Botany, 54, 845-849.

[56] Taiz L., Zeiger E. (2015) Plant Physiology and Development. 6th edition. Sinauer Assoc., Inc. Sunderland, MA, $761 \mathrm{p}$.

[57] Takezawa D., Liu Z.H., An G., Poovaiah B.W. (1995) Calmodulin gene family in potato: developmental and touch-induced expression of the mRNA encoding a novel isoform. Plant Molecular Biology, 27, 693-703.

[58] Telewski F.W. (1990) Growth, wood density, and ethylene production in response to mechanical perturbation in Pinus taeda. Canadian Journal of Forestry Research, 20, 1277-1282.

[59] Telewski F.W. (1995) Wind-induced physiological and developmental responses in trees. In:Wind and Trees. Coutts, M.P., Grace, J. (Eds.), Cambridge University, Cambridge, pp. 237263.

[60] Telewski F.W., Jaffe M.J. (1986a) Thigmomorphogenesis: field and laboratory studies of Abies fraseri in response to wind or mechanical perturbation. Physiologia Plantarum, 66, 211-218.

[61] Telewski F.W., Jaffe M.J. (1986b) Thigmomorphogenesis: anatomical, morphological, and mechanical analysis of genetically different sibs of Pinus taeda in response to mechanical perturbation. Physiologia Plantarum, 66, 227-233.

[62] Telewski F.W., Pruyn M.L. (1998) Thigmomorphogenesis: a dose response to flexing in Ulmus americana L. seedlings. Tree Physiology, 18, 65-68.

[63] Vogel S. (1992) Twist-to-bend ratios and cross-sectional shapes of petioles and stems. Journal of Experimental Botany, 43, 1527-1532.

[64] Wainwright S.A., Biggs W.D., Currey J.D., Gosline J.M. (1982) Mechanical Design of Organisms. Princeton University Press, Princeton, 423 p.

[65] Whitehead F.H. (1962) Experimental studies of the effect of wind on plant growth and anatomy II. Helianthus annuus. New Phytologist, 61, 59-62.

[66] Yoo B.C., Lee J.Y., Lucas W.J. (2002) Analysis of the complexity of protein kinases within the phloem sieve tube system. Characterization of Cucurbita maxima CALMODULIN-LIKE DOMAIN PROTEIN KINASE 1. The Journal of Biological Chemistry, 277, 15325-15332. 